\title{
J-bone graft with double locking plate: a symphony of mechanics and biology for atrophic distal femoral non-union with bone defect
}

\author{
Jian $\mathrm{Lu}^{1,3+}$, Shang-Chun Guo ${ }^{2+}$, Qi-Yang Wang ${ }^{1}$, Jia-Gen Sheng ${ }^{1 *}$ (1) and Shi-Cong Tao ${ }^{1 *}$ (D)
}

\begin{abstract}
Objective: Atrophic distal femur non-union with bone defect (ADFNBD) has been a worldwide challenge to treat due to the associated biological and mechanical problems. The purpose of this study was to introduce a new solution involving the use of a J-shaped iliac crest bone graft (J-bone) combined with double-plate (DP) in the treatment of femoral non-union.

Methods: Clinically, 18 patients with ADFNBD were included in this retrospective study and were treated with a combination of J-bone graft and DP. The average follow-up time was $22.1 \pm 5.5$ months (range, 14 to 34 months). The imaging information and knee joint activity tests and scores were used to evaluate the time to weight-bearing, the time to non-union healing, and the knee joint mobility. A finite element analysis was used to evaluate the differences between the following: (1) the use of a lateral locking plate (LLP) only group (LLP-only), (2) a DP only group (DP-only), (3) a DP with a J-bone group (DP+J-bone), and (4) an LLP with a J-bone group (LLP+J-bone) in the treatment of ADFNBD. A finite element analysis ABAQUS 6.14 (Dassault systems, USA) was used to simulate the von Mises stress distribution and model displacement of the plate during standing and normal walking.

Result: All patients with non-union and bone defect in the distal femur achieved bone healing at an average of $22.1 \pm$ 5.5 months (range, 14 to 34 months) postoperatively. The average healing time was $6.72 \pm 2.80$ months. The knee Lysholm score was significantly improved compared with that before surgery. Under both $750 \mathrm{~N}$ and $1800 \mathrm{~N}$ axial stress, the maximum stress with the DP+J-bone structure was less than that of the LLP+J-bone and DP-only structures, and the maximum stress of J-bone in the DP+J-bone was significantly less than that of the LLP+J-bone+on structure. The fracture displacement of the DP+J-bone structure was also smaller than that of the LLP+J-bone and DP-only structures.

Conclusion: J-bone combined with DP resulted in less maximum stress and less displacement than did a J-bone combined with an LLP or a DP-only graft for the treatment of ADFNBD. This procedure was associated with less surgical trauma, early rehabilitation exercise after surgery, a high bone healing rate, and a satisfactory rate of functional recovery. Therefore, a combination of J-bone and DP is an effective and important choice for the treatment of ADFNBD.
\end{abstract}

Keywords: Distal femur non-union with bone defect, J-shaped iliac crest bone graft, Finite element analysis

\footnotetext{
*Correspondence: shengjiagen@126.com; jerrytao1990@outlook.com

†Jian Lu and Shang-Chun Guo are co-first authors.

'Department of Orthopaedic Surgery, Shanghai Jiao Tong University Affiliated Sixth People's Hospital, 600 Yishan Road, Shanghai 200233, China

Full list of author information is available at the end of the article
}

C C The Author(s). 2020 Open Access This article is licensed under a Creative Commons Attribution 4.0 International License, which permits use, sharing, adaptation, distribution and reproduction in any medium or format, as long as you give appropriate credit to the original author(s) and the source, provide a link to the Creative Commons licence, and indicate if changes were made. The images or other third party material in this article are included in the article's Creative Commons licence, unless indicated otherwise in a credit line to the material. If material is not included in the article's Creative Commons licence and your intended use is not permitted by statutory regulation or exceeds the permitted use, you will need to obtain permission directly from the copyright holder. To view a copy of this licence, visit http://creativecommons.org/licenses/by/4.0/. The Creative Commons Public Domain Dedication waiver (http://creativecommons.org/publicdomain/zero/1.0/) applies to the data made available in this article, unless otherwise stated in a credit line to the data. 


\section{Introduction}

Distal femoral fracture is a rare type of fracture with a reported incidence of $8.7 / 100,000 /$ year in 2005-2010 [1]. These fractures are caused by high-energy damage in young people or low-energy damage in the elderly with concomitant osteoporosis. Retrospective studies have reported that the complication rates of malunion, non-union, infection, or death after distal femoral fracture are as high as $15-20 \%$ [2-5]. Due to the anatomical shape of the femur [6] and the mechanical effect of the distal femur, atrophic distal femoral non-union with bone defect (ADFNBD) is one of the most difficult subtypes of distal femoral non-union [7] and varus deformity with medial posterior bone defect [8]. Poor bone mass and bone defects at the distal femur present a huge challenge for orthopedic surgeons around the world.

The greatest challenge in the treatment of ADFNBD is how to provide sufficient stability and potential for osteogenesis. A J-shaped iliac crest is a bicortical structural bone graft [9-11] used in the conventional surgical procedure for reconstructing the articular hernia to resolve shoulder instability.

The purpose of this study was to demonstrate a possible new method called double-plate with J-bone for treating ADFNBD. In theory, the J-bone provides superior autologous bone osteogenesis, and its bicortical structure can overcome the lack of stability of the medial posterior side. Therefore, a main lateral locking plate (LLP), a protective medial locking plate (MLP), and a supporting J-bone can be applied for treating ADFNBD.

In this study, multiple groups of models were constructed using finite element analysis, and the maximum stress and changes in fracture clearance of the internal fixation and J-bone were compared under simulated standing and normal walking conditions. Preoperative and postoperative radiographic data and knee joint evaluation scales were also used to evaluate the effectiveness of a steel double-plate (DP) combined with a Jbone for the treatment of ADFNBD.

\section{Methods \\ Clinical investigation \\ Patients and methods}

This study protocol was approved by the independent ethics committee of the Shanghai Sixth People's Hospital Review Committee. All patients provided informed consent. The patient inclusion criteria were as follows: (1) non-union, defined as failure of fracture healing over at least 9 months or no evidence of progressive healing over three consecutive months [12], and imaging evidence supporting the diagnosis of atrophic non-union; (2) voluntarily choosing to use a double-plate with a J-bone; (3) voluntary participation in clinical trials; and (4) signing of an "informed consent for operation" form. Eighteen patients treated between Jan 2017 and Sept 2018 who met the inclusion criteria were enrolled. The details of these patients are shown in Table 1.

\section{Surgical technique}

The four surgical methods are all in under general anesthesia; all patients were placed in a supine position. First, the bicortical iliac crest bone graft was harvested and prepared as previously described [13, 14]. After molding of the bicortical iliac crest graft with an oscillating saw and a high-speed burr in a J-shaped fashion, the outside of the femur was exposed along the previous outer lateral incision on the thigh and the original internal fixation was removed to further expose the non-union of bone. Next, the scar tissue, original callus, sclerotic bone, and dead bone were removed, and the medullary cavity of the broken ends was opened on both sides. After adjusting the limb length, rotation, and angulation of the fracture, it was stabilized temporarily using a K-wire, and a long LLP was subsequently placed outside the fractured femur. Next, a minimally invasive longitudinal incision $(3-7 \mathrm{~cm})$ was made on the medial side of the non-union site, followed by deep dissection to expose the non-union. The keel of the J-bone graft was impacted on the graft with a mallet into the medial defect to obtain press-fit fixation. Finally, the medial locking compression plate (LCP) (3.5-mm hole) was fixed to the medial side of the distal femur for protection and support (Fig. 5). The drainage tube was routinely placed for no more than $72 \mathrm{~h}$ after surgery to prevent postoperative hematoma. All patients were treated with antibiotics to prevent infection.

The other three surgical methods also used the original longitudinal incision, and all removed the original internal fixation and clear scar tissue and dead bones. In the LLP-only group, a long LCP was fixed on the outside of the fracture femur. On the basic of LLP-only group, the LP+J-bone group also tapped the trimmed J-shaped iliac crest bone graft (J-bone) as described earlier on the medial side of distal femur after removed scar tissue and dead bone. Different from $\mathrm{LP}+\mathrm{J}$-bone, the DP group added a $3.5-\mathrm{mm}$ medial LCP which was fixed on the medial side of the distal femur through a medial incision. Cancellous bone pieces are employed, in all groups, to promote bone healing in defects.

\section{Postoperative management}

All patients were advised to perform active functional exercises for the quadriceps on the first postoperative day. Active function of the knee joint was assessed 2 weeks after surgery. Partial weight-bearing was permitted 4 weeks after surgery based on the clinical and imaging evidence of fracture healing.

The patients were evaluated using imaging data (CT scan) and functional tests (Lysholm Knee Scoring Scale scores [15]) 1, 3, 6, and 12 months after surgery. Bone healing was defined as the absence of bone or weightless pain in the non-union site and the presence of three cortical bridges on the anterior and lateral imaging data. 
Table 1 Details of patients treated with a J-bone combined with a steel double-plate for distal femoral non-union with a bone

\begin{tabular}{|c|c|c|c|c|c|c|c|c|}
\hline $\begin{array}{l}\text { Patient } \\
\text { number }\end{array}$ & $\begin{array}{l}\text { Age } \\
\text { (years) }\end{array}$ & Sex & $\begin{array}{l}\text { Mechanism } \\
\text { of injury }\end{array}$ & $\begin{array}{l}\text { Interval between } \\
\text { non-union (months) }\end{array}$ & $\begin{array}{l}\text { Previous } \\
\text { treatment }\end{array}$ & $\begin{array}{l}\text { Time to union } \\
\text { (months) }\end{array}$ & Complication & $\begin{array}{l}\text { Follow-up } \\
\text { (months) }\end{array}$ \\
\hline 1 & 41 & $\mathrm{~F}$ & MVA & 20 & LLP & 6 & None & 34 \\
\hline 2 & 54 & M & MVA & 12 & LLP & 8 & SWI & 29 \\
\hline 3 & 49 & M & MVA & 24 & LLP & 6 & None & 28 \\
\hline 4 & 28 & M & MVA & 10 & LLP & 8 & None & 27 \\
\hline 5 & 62 & M & FALL & 5 & LLP & 6 & None & 27 \\
\hline 6 & 59 & M & MVA & 4 & LLP & 3 & None & 26 \\
\hline 7 & 35 & F & MVA & 24 & LLP & 12 & None & 25 \\
\hline 8 & 42 & F & MVA & 13 & LLP & 3 & None & 22 \\
\hline 9 & 48 & F & MVA & 48 & LLP & 6 & None & 20 \\
\hline 10 & 48 & M & Injury & 9 & LLP & 6 & Knee stiffness & 20 \\
\hline 11 & 63 & F & MVA & 7 & LLP & 6 & SWI & 20 \\
\hline 12 & 53 & F & MVA & 12 & LLP & 9 & None & 20 \\
\hline 13 & 49 & $\mathrm{~F}$ & MVA & 9 & LLP & 12 & None & 19 \\
\hline 14 & 35 & M & Injury & 10 & LLP & 9 & None & 19 \\
\hline 15 & 47 & M & MVA & 9 & LLP & 3 & None & 18 \\
\hline 16 & 60 & F & MVA & 6 & LLP & 3 & None & 16 \\
\hline 17 & 39 & F & MVA & 10 & LLP & 9 & None & 14 \\
\hline 18 & 47 & $M$ & MVA & 48 & LLP & 6 & None & 14 \\
\hline
\end{tabular}

LLP lateral locking plate, $F$ female, $M$ male, $M V A$ motor vehicle accident, SWI superficial wound infection

\section{Finite element analysis}

\section{Three-dimensional models}

Using enhanced computed tomography (CT) with slicing of $0.625 \mathrm{~mm}$ at a $20-\mathrm{cm}$ slice distance, the femur of a healthy young male (age 20 years, height $178 \mathrm{~cm}$, body weight 85 $\mathrm{kg}$ ) was scanned to obtain raw imaging data of a normal femur. Informed consent was obtained from the subject to use his radiologic data for research purposes. The images, in Digital Imaging and Communications in Medicine (DICOM) format, were imported into Mimics 20.0 (The Materialise Group, Leuven, Belgium) in order to generate a three-dimensional (3D) model. Bone mineral density parameters were calculated according to the following equation by Reina-Romo et al. [16] based on CT data:

$$
\begin{aligned}
& \rho=0.000968 \times \mathrm{HU}+0.5,\left(\mathrm{~g} / \mathrm{cm}^{3}\right) \\
& E=\left\{\begin{array}{cc}
2014 \rho^{2.5},(\mathrm{MPa}) & \rho \text { no more than } 1.2 \mathrm{~g} / \mathrm{cm}^{3} \\
1763 \rho^{3.2},(\mathrm{MPa}) & \rho \text { granter than } 1.2 \mathrm{~g} / \mathrm{cm}^{3}
\end{array}\right.
\end{aligned}
$$

$$
v=\left\{\begin{array}{cc}
0.20, & \rho \text { no more than } 1.2 \mathrm{~g} / \mathrm{cm}^{3} \\
0.32, & \rho \text { granter than } 1.2 \mathrm{~g} / \mathrm{cm}^{3}
\end{array}\right.
$$

The Geomagic software was used to sample and build the geometry and surface, and the resulting basic 3D model was compiled and meshed in HyperMesh 14.0 (Altair Engineering Inc., Troy, MI, USA). In 3-Matic 11.0 (Materialise, Leuven,
Belgium), a 15-mm transverse osteotomy plane of $6.5 \mathrm{~cm}$ was made near the joint line to simulate distal femur mechanical structure instability with bone defect $[17,18]$.

According to the blueprint provided by the manufacturer, the LLP, MP, and screws (Synthes, 3.5-mm LCP) were designed and modified using Solid Works 14.0 (Dassault Systèmes Solid Works Corp., Concord, MA, USA). The geometric parameters of plates and screws were loaded into 3-Matic 11.0 (Materialise, Leuven, Belgium), and four case models were established according to the experiment (Fig. 1). The threaded surface of the screw was replaced by a smooth surface, and the size of the surface corresponded to the screw data provided by the manufacturer [19]. Finally, HyperMesh 14.0 (Altair Engineering Inc., Troy, MI, USA) was used to mesh these combined models into $1 \mathrm{~mm}$, and a finite element model was developed for mechanical analysis with ABAQUS 6.14 (Dassault Systèmes Solid Works Corp., Concord, MA, USA).

\section{Material properties and boundary conditions}

We assumed that both the femur and the strut were linear, isotropic, and elastic [20]. Cortical and trabecular bones were assigned a Young's modulus (E) of 16.7 GPa and $0.155 \mathrm{GPa}$, respectively, and the Poisson's ratios were 0.26 and $0.3[17,21]$, respectively (Table 2 ). The less invasive stabilization system (LISS) plate, medial plate, and screws were made of a titanium alloy (Ti-6AL-4V) (Table 


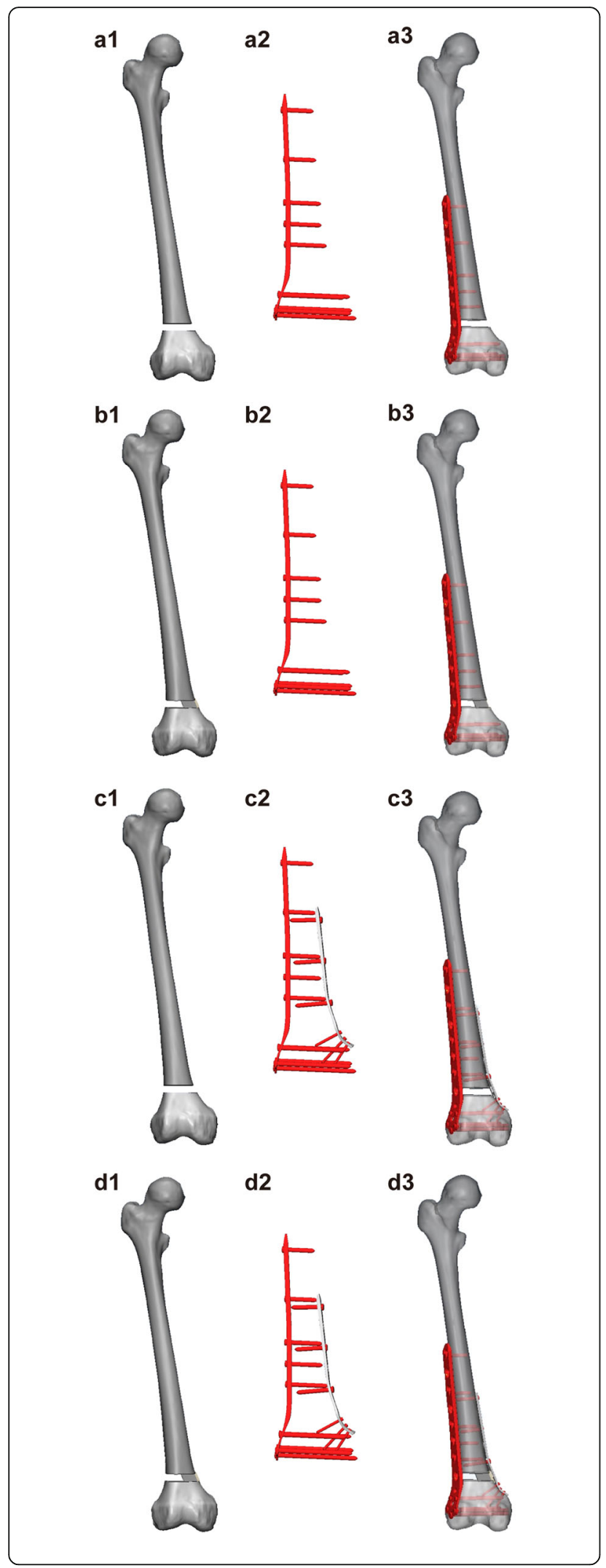

Fig. 1 Construction of the four three-dimensional models. a1-a3: model 1 is built with only a lateral locking plate (LLP-only); b1-b3: model 2 is built with a J-bone+LLP; C1-c3: model 3 is built with only a double locking plate (DP-only); d1-d3: model 4 is built with Jbone+DP. LLP lateral locking plate, DP double-plate

2). According to early scholars [22, 23], the interface between the plate and the screws was modeled using a surface-surface contact element that allows separation and sliding. Considering that the internal fixation was locked, the rigid connection between the screws and the plate holes was simulated [24]. The friction coefficient of bone and bone interaction was 0.46 , and that of bone and implant interaction was 0.3 [25]. In order to prevent rigid motion during the analysis, the femoral head was limited to a plane perpendicular to the loading vector, and the distal femur was fixed in all degrees of freedom [26].

In this study, all models were tested with $750 \mathrm{~N}$ (oneleg standing load force of $100 \%$ of the body weight [27]) and $1800 \mathrm{~N}$ (normal walking load force $238 \%$ body weight [28]) of adduction loads applied. The lateral displacement ( $\mathrm{aa}$ '), middle displacement (bb'), and medial displacement (cc') at the non-union gap were calculated and the change in height was observed (Fig. 2).

FEA

ABAQUS 6.14 (Dassault Systèmes, Solid Works Corp., Concord, MA, USA) was used to obtain the von Mises stress distribution of the LCP and J-bone during simulated standing and normal walking. Axial fretting was measured at the end gap to detect the stability of the model.

\section{Statistical analyses}

SPSS statistical software package 24.0 (SPSS Inc., Chicago, IL, USA) was used to analyze the relevant data. The chi-square test was used to compare the preoperative and postoperative "excellent" and "good" scores, and $P<0.05$ was considered statistically significant.

\section{Results}

Results of the clinical study

Eighteen patients (nine females and nine males, mean age 47.7 years, range $28-62$ years) were operated on using a DP with a J-bone. All 18 patients achieved primary bone healing, and the mean time to weight-bearing walking was 5.5 months (range 3-12 months) after surgery. At the last follow-up, no patients had developed postoperative limb

Table 2 Material properties used for each type of structure

\begin{tabular}{llll}
\hline Components & Ti-6AL-4V & Bone & \\
\cline { 3 - 4 } & & Cortical & Trabecular \\
\hline Young's modulus (GPa) & 105 & 16.7 & 0.155 \\
Poisson's ratio & 0.35 & 0.26 & 0.3 \\
\hline
\end{tabular}


a

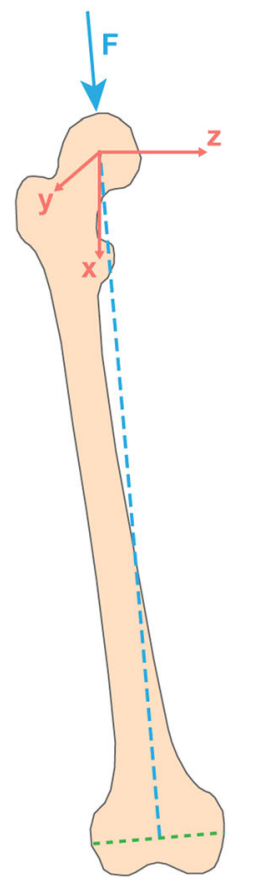

b

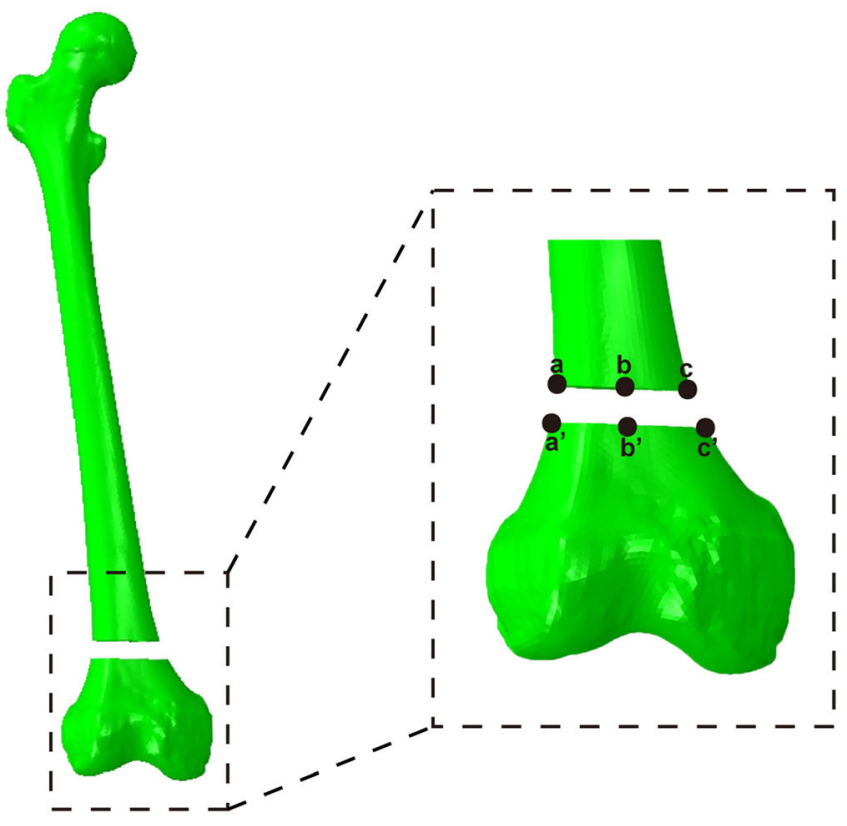

Fig. 2 Calculations of loading force and fracture gap. a Schematic of the loading force from the focal point of the femoral head to the midpoint of the femoral condyle. $\mathbf{b}$ Three lines from a to $\mathrm{a}^{\prime}$, from $b$ to $b^{\prime}$, and from $c$ to $c c^{\prime}$ are used to calculate the axial micromotion of the fracture gap

malformations (more than $5^{\circ}$ in the coronal, sagittal, or rotational deformities, or more than $1 \mathrm{~cm}$ in leg length). The rate of "excellent" and "good" Lysholm Knee Scoring Scale scores improved from 0\% before surgery to $94.44 \%$ at 3 months after surgery (Table 3). Three patients had surgery-related complications. Two of them developed a superficial wound infection, which was normalized by irrigation and debridement. There was also one case of knee stiffness. After the non-union was healed, the function of the knee joint was improved by removing the internal fixation and releasing the quadriceps.

Figure 5 shows imaging data of patient 1 from the time of trauma to the time of treatment and follow-up.

\section{Results of the FEA}

The numerical values of the stress distribution of each treatment group are shown in Table 4. Under $750 \mathrm{~N}$ of axial force, higher stress was found with the LLP-only graft and may have led to a higher risk of failure; however, the specific value could not be calculated. Maximum stress was placed on the J-bone in DP+J-bone and LLP+J-bone graft structures on the cortical bone on the medial and posterior sides of the distal femur, and the J-bone of the DP with a Jbone graft was significantly smaller than that of the LLP with a J-bone. Furthermore, under the axial stress of $750 \mathrm{~N}$, the plate for the DP-only structure was under 1.38 times and 1.26 times as much stress as the DP+J-bone and LLP+J-bone structures, respectively (Fig. 3). Under $1800 \mathrm{~N}$ stress, the mean stresses around the plate for the DP-only structure were 1.36 times greater than that of the $\mathrm{DP}+\mathrm{J}$ bone group and 1.07 times greater than that of the LLP+Jbone group (Fig. 4).

The model displacement values for different loads in the three implant groups are shown in Table 5.

\section{Discussion}

Non-infectious distal femoral non-union can be divided into hypertrophic non-union and atrophic non-union according to the imaging data. Hypertrophic non-union requires replacement with a stronger fixing device due to a lack of good mechanical fixation. The fracture end of atrophic non-union lacks callus and cartilage due to lack of

Table 3 Comparison of Lysholm Knee Scoring Scale scores before and after surgery

\begin{tabular}{|c|c|c|c|c|c|c|}
\hline & \multirow[t]{2}{*}{$N$} & \multicolumn{4}{|c|}{ Lysholm Knee Scoring Scale } & \multirow{2}{*}{$\begin{array}{l}\text { Excellent and } \\
\text { good rate }\end{array}$} \\
\hline & & Excellent & Good & Fair & Poor & \\
\hline Preoperative & 18 & $0(0.00)$ & $0(0.00)$ & $10(55.56)$ & $8(44.44)$ & $0(0.00) *$ \\
\hline Postoperative (3 months) & 18 & $2(11.11)$ & $15(83.33)$ & $1(5.56)$ & $0(0.00)$ & $17(94.44)$ \\
\hline
\end{tabular}

Data are presented as number (percentage)

${ }^{*} P<0.05$, preoperative vs. postoperative at 3 months 
Table 4 Maximum (mean) values of stress on the plate and J-bone in the three models under two levels of stress loading

\begin{tabular}{|c|c|c|c|c|c|}
\hline \multirow{2}{*}{$\begin{array}{l}\text { Adduction } \\
\text { load }(\mathrm{N})\end{array}$} & \multicolumn{2}{|l|}{ DP+J-bone } & \multicolumn{2}{|l|}{ LLP+J-bone } & \multirow{2}{*}{$\begin{array}{l}\text { DP-only } \\
\text { Plate (MPa) }\end{array}$} \\
\hline & Plate (MPa) & J-bone (MPa) & Plate (MPa) & J-bone (MPa) & \\
\hline 750 & 192 & 41 & 210 & 61 & 264 \\
\hline 1800 & 715 & 134 & 907 & 213 & 970 \\
\hline
\end{tabular}

DP double-plate, LLP lateral locking plate

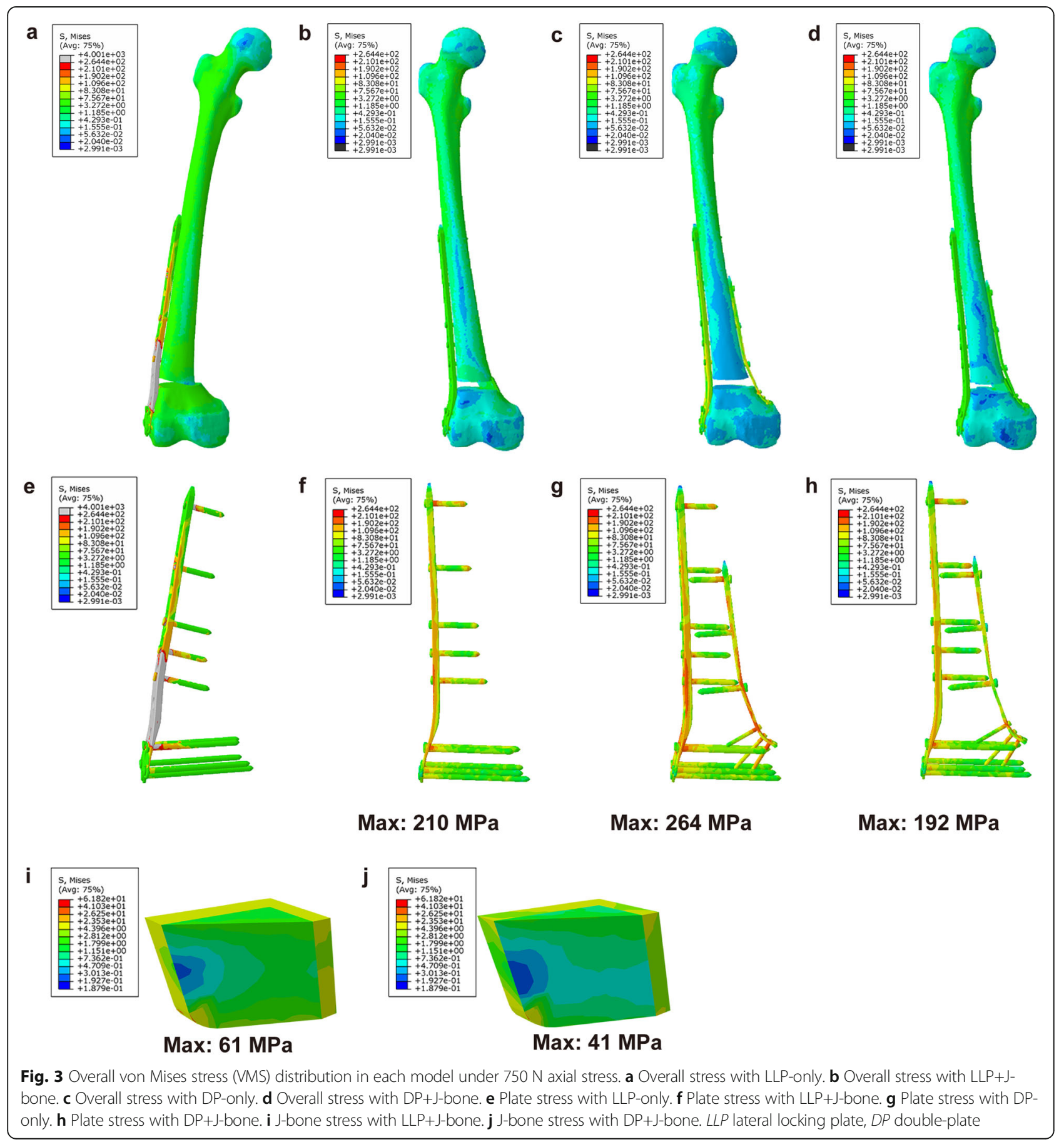


a

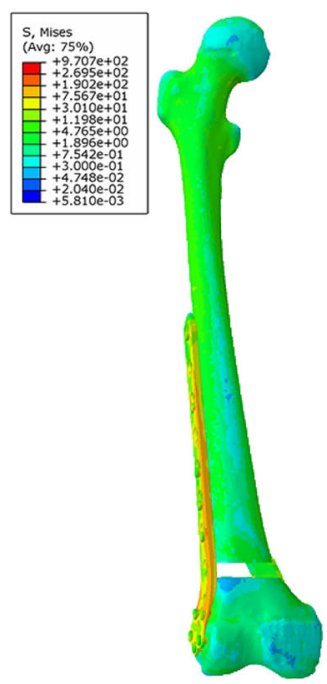

d

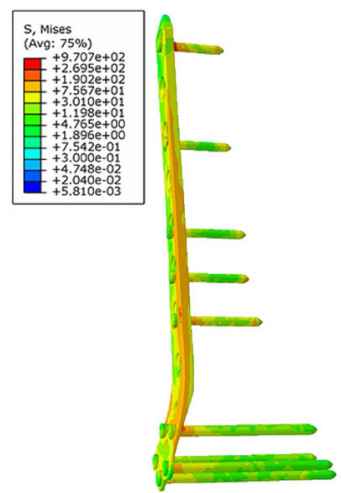

Max: $907 \mathrm{MPa}$ b

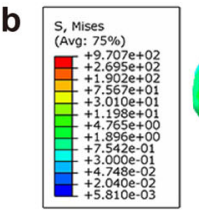

\section{$1800 \mathrm{~N}$} Addution load
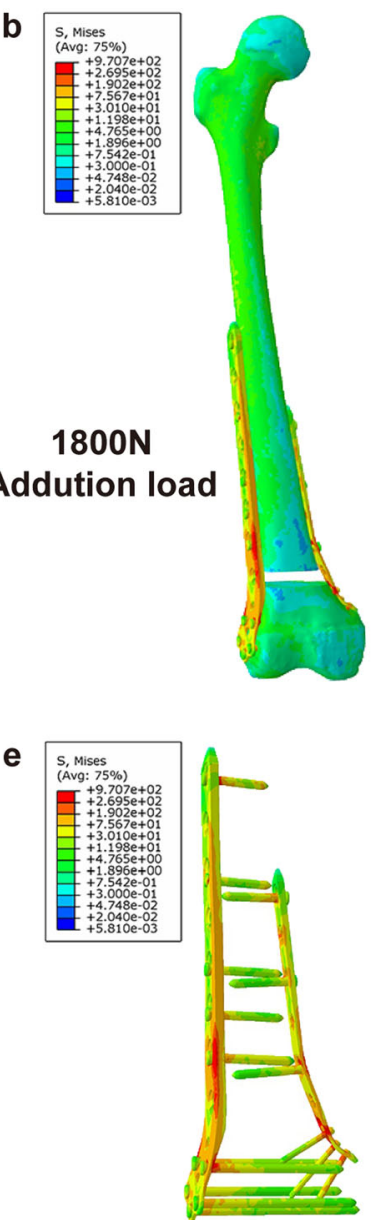

Max: $970 \mathrm{MPa}$ c
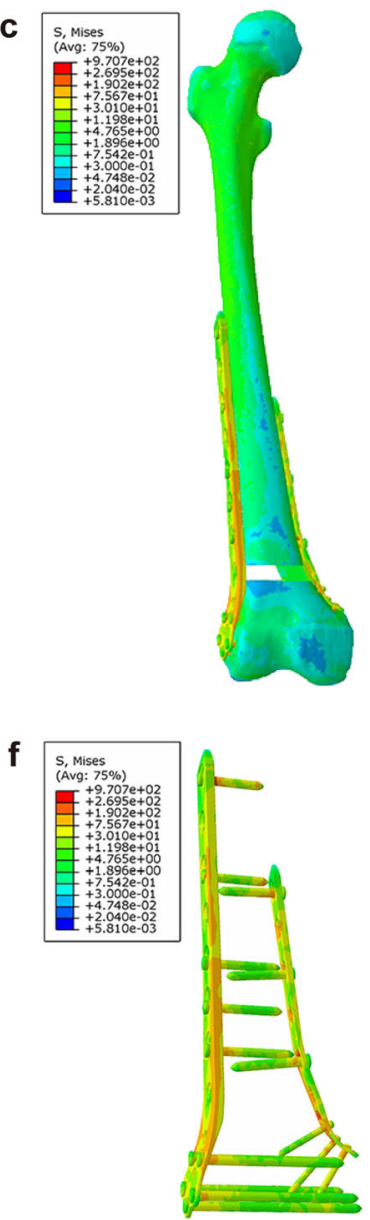

Max: $715 \mathrm{MPa}$
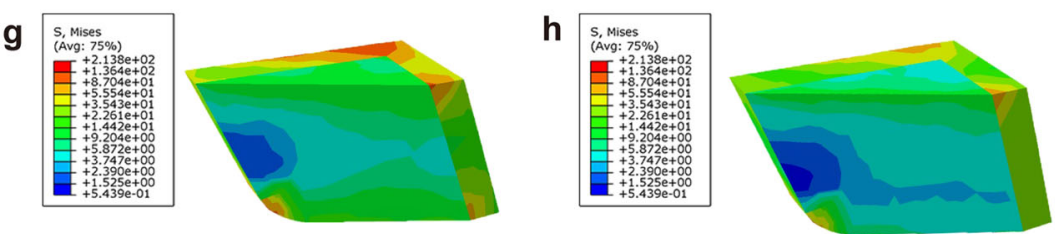

Fig. 4 Von Mises stress (VMS) distribution in each model under $1800 \mathrm{~N}$ axial stress. a Overall stress with LLP+J-bone. b Overall stress with DP-only. $\mathbf{c}$ Overall stress with DP+J-bone. $\mathbf{d}$ Plate stress with LLP+J-bone. e Plate stress with DP-only. $\mathbf{f}$ Plate stress with DP+J-bone. $\mathbf{g}$ J-bone stress with LLP+J-bone. h J-bone stress with DP+J-bone. LLP lateral locking plate, DP double-plate

Table 5 Displacement values of the non-union area of the three models under two levels of stress loading

\begin{tabular}{lllll}
\hline $\begin{array}{llll}\text { Internal } \\
\text { fixation }\end{array}$ & $\begin{array}{l}\text { Adduction } \\
\text { load }(N)\end{array}$ & \multicolumn{4}{l}{ Displacement $(\mathrm{mm})$} \\
\cline { 3 - 5 } & & $\mathrm{aa}$ & $\mathrm{bb}^{\prime}$ & $\mathrm{cC}^{\prime}$ \\
\hline DP+J-bone & 750 & 0.052 & 0.052 & 0.037 \\
LLP+J-bone & 1,800 & 0.191 & 0.213 & 0.118 \\
& 750 & 0.059 & 0.059 & 0.053 \\
DP-only & 1800 & 0.228 & 0.216 & 0.162 \\
& 750 & 0.184 & 0.185 & 0.214 \\
& 1800 & 0.766 & 0.757 & 0.840 \\
\hline
\end{tabular}

$D P$ double-plate, $L L P$ lateral locking plate, $a a^{\prime}$ lateral displacement, $b b^{\prime}$ middle displacement, $c c^{\prime}$ medial displacement cells and blood supply, leading to proliferation and hardening of large fractures and atrophy of the fracture ends; therefore, the fracture site may be sclerotic or osteopenic [29]. Additionally, the lack of bone supports on the medial and posterior sides of the distal femur can cause instability, leading to varus tendencies or rotation [6]. The anatomy of the distal femur is complex, and the fracture area is accompanied by obvious scar tissue and poor blood flow at the stump, which presents great challenges in clinical treatment. For ADFNBD, successful treatment requires restoration of a painless, well-aligned knee with a satisfactory range of motion that maintains good alignment of the 
entire lower limb. Instability is the main cause of nonunion; thus, it is better to fix it using a stable method and reduce the blood supply as little as possible [30]. A lack of bone morphogenetic cells or blood supply is also an important cause of non-union with bone defect [31] (Fig. 5).

Although there are many treatments for non-union of the distal femur, there is still no uniform standard. Previous reports have described the results of a variety of techniques for the treatment of distal femoral non-union. Intramedullary nails can minimize soft tissue injury [32, 33], but there is a risk of malunion in this correction, as well as obvious shortening of the non-union in the dynamic compression [34, 35]. The llizarov technique has the advantage of restoring the anatomical location of the non-union and increasing the stability of bone healing, leading to early weight-bearing. However, this technique is associated with a high probability of complications such as infection and the need for multiple operations [36, 37]. LCPs are favored due to their minimal trauma, small periosteal damage, and high stability [38]. Double locking plates provide continuous non-union site compression and the chance to clear dead bones. Maimaitiyiming et al. reported successful cure in 14 out of 37 patients with femoral fracture non-union using a double locking plate combined with bone grafting. Consequently, exposure of the non-union site, removal of the failed previous hardware, removal of fibrous scar tissue, correction of deformities, full bone grafting, and stable mechanical fixation are strategies for ADFNBD treatment. Jiang et al. [39] proved that the application of double locking plates with a fibular autograft is a promising method for diaphyseal femur fracture non-union; however, due to the possible complications of obtaining a graft from the fibular, it is only recommended for severe non-union. Treatment with DP combined with bicortical iliac bone provides a mechanical and biological environment, and unlike fibular grafts, it is not associated with serious complications; therefore, it may be a suitable alternative treatment.

In this study, we introduced a new method for treating ADFNBD. A total of 18 patients with non-union of the distal femur were included in this retrospective study, and these patients were treated with double-plates. The average follow-up time was 12 months. No cases of bone nonunion or internal fixation rupture occurred. Before surgery, due to the defect of the distal femur, the affected limb was not able to bear weight or engage in exercise, resulting in poor knee joint mobility. One month after the operation, the

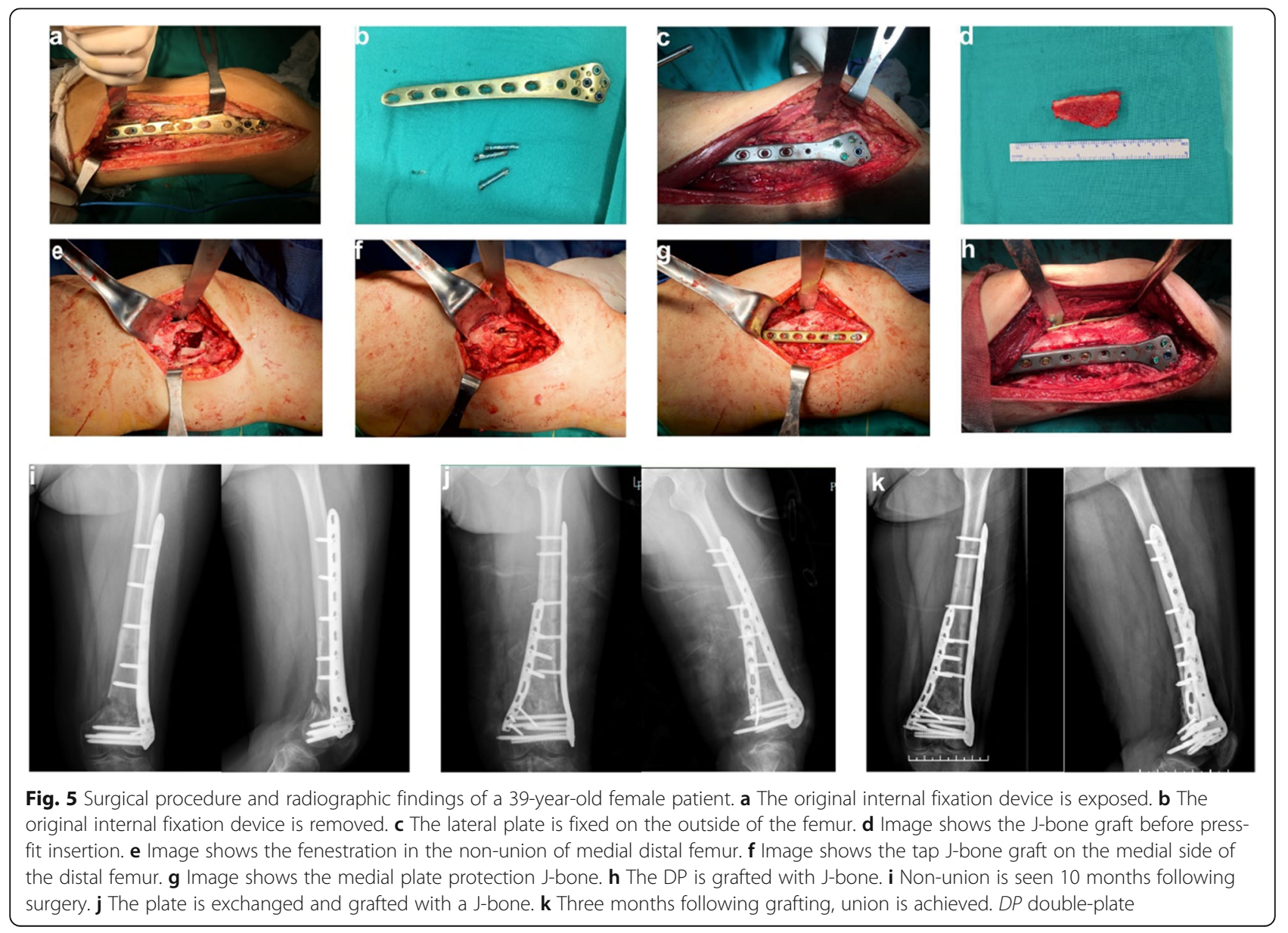


healing status was judged based on imaging data and physical examination, and guided functional exercises were started. Early recovery after surgery and knee movement satisfaction rates were higher, and the knee joint mobility in this group was significantly improved compared to that before surgery. In order to further evaluate the performance of the new configuration, we conducted a finite element analysis, and the results showed that, compared with the use of an LLP+J-bone and a DP-only, the use of a DP+J-bone showed excellent stability in both simulated standing and walking conditions. Walking is the most common exercise method for patients with lower limb fractures [40]. However, in the case of simulated walking, the maximum stress of the LCP in the DPonly $(970 \mathrm{MPa})$ and the LLP+J-bone $(907 \mathrm{MPa})$ groups exceeded the yield strength of the Ti-6Al-4V alloy (889-921 $\mathrm{MPa}$ [ [41]. Moreover, the displacement results indicated that the $\mathrm{DP}+\mathrm{J}$-bone provided higher stability than did the other two groups under $1800 \mathrm{~N}$ axial stress and allowed a linear end of the broken end of $0.2 \mathrm{~mm}$. This not only increases the formation of callus in indirect healing but also reduces the negative effects of stress occlusion.

An LLP alone not only protects the blood supply of the non-union site but also provides strong tension side stability for the femur. The LLP is different from the traditional screw-plate structure which depends on the interface of the bone and plate [42], in that its fixed angle structure prevents contact between the plate and the bone surface [43, 44]. Furthermore, an LCP can reduce the damage to the soft tissue with the aid of an insertion guide [45]. In addition, exposure of the non-union, cleaning of the dead bone, and removal of fibrous scar tissue provide a great osteogenic environment for subsequent bone grafting. Finally, the bicortical stability of the medial pressure of the J-bone limits micromotion, which creates an excellent mechanical environment for the repair of the non-union, thus promoting the indirect healing of the non-union. In addition, the J-bone is the gold standard for the treatment of non-union because of its complete histocompatibility, strong osteoinduction, osteoconduction, and osteogenic activities [46]. It is important for the J-bone to provide direct structural continuity at the site of the non-union, making up for the defect of the cancellous bone graft [47]. The medial protective plate maintains the filling and support of the J-bone so that the medial protective plate and J-bone can increase the medial compressive and bending strength and provide a reliable initial mechanical environment for local fibrous cartilage calcification and preliminary connection of the epiphysis. The medial protective plate and bicortical J-bone can also prevent the failure of the lateral plate internal fixation after surgery so that patients can recover and exercise early without delay, which is conducive to the functional recovery of the knee joints and osteophyte healing.

This study had several limitations, including clinical evidence from this study was a retrospective study, and large samples, randomized, and controlled clinical studies should be used to provide evidence. In the finite element analysis, we simplified the model without considering the effects of the actual femoral ligaments and joint capsules. But these results are enough to show the effectiveness of DP+J-bone.

In summary, a double steel plate combined with sacrum bone (J-bone) for the treatment of non-union of the distal femur with a bone defect has the advantages of less surgical trauma, early rehabilitation exercise after surgery, a high bone healing rate, and a satisfactory rate of functional recovery. Therefore, the DP+J-bone technique may be another technique for the successful treatment of ANFBD (especially in those with severe posterior medial defect).

\section{Abbreviations \\ ADFNBD: Atrophic Distal Femur Non-Union With Bone Defect; J-bone: J- shaped iliac crest bone graft; DP: Double-plate; MP: Medial plate; LLP: Lateral locking plate; LLP-only: LLP only group; DP-only: DP only group; DP+J- bone: DP with a J-bone group; LLP+J-bone: LLP with a J-bone group; LCP: Locking compression plate; 3D: Three-dimensional; CT: Computed tomography; DICOM: Digital imaging and communications in medicine; LISS: Less invasive stabilization system; FEA: Finite element analysis}

\section{Acknowledgments}

We are very grateful to the engineer, Shi Zhan, in our institute, and the biomechanics specialist, Hai Hu, for their technical support and consultation.

\section{Authors' contributions}

$J$ : data analysis and interpretation, finite element analysis, and manuscript preparation. S-CG: data acquisition and interpretation. Q-YW: data acquisition. J-GS: manuscript approval. S-CT: study design, manuscript preparation, and approval. All authors reviewed and accepted the final manuscript.

\section{Funding}

The National Natural Science Foundation of China $(81871834,81802226$, and 81301589), Shanghai Pujiang Program (2019PJD038), and Shanghai Jiao Tong University K. C. Wong Medical Fellowship Fund supported this study.

Availability of data and materials

Please contact author for data requests.

Ethics approval and consent to participate

The clinical data collection of this article was approved by the Independent Ethics Committee of the Evaluation Committee of Shanghai Sixth People's Hospital.

Consent for publication

Not applicable.

\section{Competing interests}

The authors declare that they have no competing interests.

\section{Author details}

${ }^{1}$ Department of Orthopaedic Surgery, Shanghai Jiao Tong University Affiliated Sixth People's Hospital, 600 Yishan Road, Shanghai 200233, China. ${ }^{2}$ Institute of Microsurgery on Extremities, Shanghai Jiao Tong University Affiliated Sixth People's Hospital, 600 Yishan Road, Shanghai 200233, China. ${ }^{3}$ The Third Affiliated Hospital of Soochow University, Changzhou 213003, Jiangsu, China.

Received: 23 January 2020 Accepted: 13 March 2020

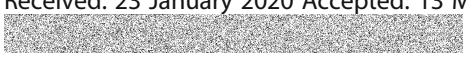

\section{References}

1. Koso RE, Terhoeve C, Steen RG, Zura R. Healing, nonunion, and re-operation after internal fixation of diaphyseal and distal femoral fractures: a systematic review and meta-analysis. Int Orthop. 2018;42(11):2675-83. 
2. Brumback RJ, Uwagie-Ero S, Lakatos RP, Poka A, Bathon GH, Burgess AR. Intramedullary nailing of femoral shaft fractures. Part II: fracture-healing with static interlocking fixation. J Bone Joint Surg Am. 1988;70(10):1453-62.

3. Gardner MJ, Boraiah S, Helfet DL, Lorich DG. Indirect medial reduction and strut support of proximal humerus fractures using an endosteal implant. J Orthop Trauma. 2008;22(3):195-200.

4. Meneghini RM, Keyes BJ, Reddy KK, Maar DC. Modern retrograde intramedullary nails versus periarticular locked plates for supracondylar femur fractures after total knee arthroplasty. J Arthroplasty. 2014;29(7):1478-81.

5. Chen SH, Chiang MC, Hung CH, Lin SC, Chang HW. Finite element comparison of retrograde intramedullary nailing and locking plate fixation with/without an intramedullary allograft for distal femur fracture following total knee arthroplasty. Knee. 2014;21(1):224-31.

6. Apel DM, Patwardhan A, Pinzur MS, Dobozi WR. Axial loading studies of unstable intertrochanteric fractures of the femur. Clin Orthop Relat Res. 1989;246:156-64

7. Koval KJ, Seligson D, Rosen H, Fee K. Distal femoral nonunion: treatment with a retrograde inserted locked intramedullary nail. J Orthop Trauma. 1995;9(4):285-91.

8. Bellabarba C, Ricci WM, Bolhofner BR. Indirect reduction and plating of distal femoral nonunions. J Orthop Trauma. 2002;16(5):287-96.

9. Moroder P, Blocher M, Auffarth A, Hoffelner T, Hitzl W, Tauber M, Resch H. Clinical and computed tomography-radiologic outcome after bony glenoid augmentation in recurrent anterior shoulder instability without significant glenoid bone loss. J Shoulder Elbow Surg. 2014;23(3):420-6.

10. Tauber M, Resch H, Forstner R, Raffl M, Schauer J. Reasons for failure after surgical repair of anterior shoulder instability. J Shoulder Elbow Surg. 13(3):279-85.

11. Anderl W, Pauzenberger L, Laky B, Kriegleder B, Heuberer PR. Arthroscopic implant-free bone grafting for shoulder instability with glenoid bone loss: clinical and radiological outcome at a minimum 2-year follow-up. Am J Sports Med. 2016:44(5):1137-45.

12. Lu J, Wang QY, Sheng JG. Exosomes in the repair of bone defects: nextgeneration therapeutic tools for the treatment of nonunion. Biomed Res Int 2019;2019:1983131.

13. Moroder P, Hirzinger $C$, Lederer S, Matis N, Hitzl W, Tauber M, Resch H, Auffarth A. Restoration of anterior glenoid bone defects in posttraumatic recurrent anterior shoulder instability using the J-bone graft shows anatomic graft remodeling. Am J Sports Med. 2012:40(7):1544-50.

14. Moroder P, Plachel F, Becker J, Schulz E, Abdic S, Haas M, Resch H, Auffarth A. Clinical and radiological long-term results after implant-free, autologous, iliac crest bone graft Procedure for the treatment of anterior shoulder instability. Am J Sports Med. 2018;46(12):2975-80.

15. Hantes M, Fyllos A, Papageorgiou F, Alexiou K, Antoniou I. Long-term clinical and radiological outcomes after multiligament knee injury using a delayed ligament reconstruction approach: A single-center experience Knee. 2019;26(6):1271-7.

16. Reina-Romo E, Rodríguez-Vallés J, Sanz-Herrera JA. In silico dynamic characterization of the femur: Physiological versus mechanical boundary conditions. Med Eng Phys. 2018.

17. Zhang W, Li J, Zhang H, Wang M, Li L, Zhou J, Guo H, Li Y, Tang P. Biomechanical assessment of single LISS versus double-plate osteosynthesis in the AO type 33C2 fractures: a finite element analysis. Injury. 2018:49(12):2142-6.

18. El Haj M, Khoury A, Mosheiff R, Liebergall M, Weil YA. Orthogonal double plate fixation for long bone fracture nonunion. Acta Chir Orthop Traumatol Cech. 2013:80(2):131-7.

19. Zhang H, Li J, Zhou J, Li L, Hao M, Wang K, Xu G, Li C, Zhang W, Tang P. Finite element analysis of different double-plate angles in the treatment of the femoral shaft nonunion with no cortical support opposite the primary lateral plate. Biomed Res Int. 2018;2018:3267107.

20. Grassi L, Väänänen SP, Amin Yavari S, Weinans H, Jurvelin JS, Zadpoor AA, Isaksson $\mathrm{H}$. Experimental validation of finite element model for proximal composite femur using optical measurements. J Mech Behav Biomed Mater. 2013;21:86-94

21. Qiu TX, Teo EC, Yan YB, Lei W. Finite element modeling of a 3D coupled foot-boot model. Med Eng Phys. 2011;33(10):1228-33.

22. Eberle S, Gerber C, von Oldenburg G, Hogel F, Augat P. A biomechanical evaluation of orthopaedic implants for hip fractures by finite element analysis and in-vitro tests. Proc Inst Mech Eng H. 2010;224(10):1141-52.

23. Luo CA, Lin SC, Hwa SY, Chen CM, Tseng CS. Biomechanical effects of plate area and locking screw on medial open tibial osteotomy. Comput Methods Biomech Biomed Engin. 2015;18(12):1263-71.
24. Luo CA, Hua SY, Lin SC, Chen CM, Tseng CS. Stress and stability comparison between different systems for high tibial osteotomies. BMC Musculoskelet Disord. 2013;14:110.

25. Nuño N, Amabili M, Groppetti R, Rossi A. Static coefficient of friction between Ti-6Al-4V and PMMA for cemented hip and knee implants. J Biomed Mater Res. 2002;59(1):191-200.

26. Goffin JM, Pankaj P, Simpson AH. The importance of lag screw position for the stabilization of trochanteric fractures with a sliding hip screw: a subjectspecific finite element study. J Orthop Res. 2013;31(4):596-600.

27. Fu J, Ni M, Chen J, Li X, Chai W, Hao L, Zhang G, Zhou Y. Reconstruction of severe acetabular bone defect with 3d printed Ti6Al4V augment: a finite element study. Biomed Res Int. 2018;2018:6367203.

28. Radcliffe IA, Taylor M. Investigation into the affect of cementing techniques on load transfer in the resurfaced femoral head: a multi-femur finite element analysis. Clin Biomech (Bristol, Avon). 2007;22(4):422-30.

29. Jones $C B$, Mayo KA. Nonunion treatment: iliac crest bone graft techniques. J Orthop Trauma. 2005;19(10 Suppl):S11-3.

30. Weber BG, Cech O: Pseudoarthrosis: pathology biomechanics therapy results berne 1976.

31. Calori GM, Mazza EL, Mazzola S, Colombo A, Giardina F, Romano F, Colombo M. Non-unions. Clin Cases Miner Bone Metab. 2017;14(2):186-8.

32. Griffin XL, Costa ML, Phelps E, Parsons N, Dritsaki M, Achten J, Tutton E, Lerner RG, McGibbon A, Baird J. Intramedullary nails versus distal locking plates for fracture of the distal femur: results from the Trial of Acute Femoral Fracture Fixation (TrAFFix) randomised feasibility study and process evaluation. BMJ open. 2019;9(5):e026810.

33. Pekmezci M, McDonald E, Buckley J, Kandemir U. Retrograde intramedullary nails with distal screws locked to the nail have higher fatigue strength than locking plates in the treatment of supracondylar femoral fractures: a cadaver-based laboratory investigation. Bone Joint J. 2014:(1):96-b, 114-121.

34. Kempf I, Grosse A, Rigaut P. The treatment of noninfected pseudarthrosis of the femur and tibia with locked intramedullary nailing. Clin Orthop Relat Res. 1986:212:142-54.

35. McLaren AC, Blokker CP. Locked intramedullary fixation for metaphyseal malunion and nonunion. Clin Orthop Relat Res. 1991;265:253-60.

36. Abdel-Aal AM. Ilizarov bone transport for massive tibial bone defects. Orthopedics. 2006;29(1):70-4.

37. Zhang $H$, Xue F, Jun Xiao H. llizarov method in combination with autologous mesenchymal stem cells from iliac crest shows improved outcome in tibial non-union. Saudi J Biol Sci. 2018;25(4):819-25.

38. Kubiak EN, Fulkerson E, Strauss E, Egol KA. The evolution of locked plates. J Bone Joint Surg Am. 2006;88(Suppl 4):189-200.

39. Jiang Y, Guo YF, Meng YK, Zhu L, Chen AM. A report of a novel technique: the comprehensive fibular autograft with double metal locking plate fixation (CFALP) for refractory post-operative diaphyseal femur fracture nonunion treatment. Injury-Int J Care Inj. 2016;47(10):2307-11.

40. Morlock M, Schneider E, Bluhm A, Vollmer M, Bergmann G, Muller V, Honl $M$. Duration and frequency of every day activities in total hip patients. J Biomech. 2001;34(7):873-81.

41. Yang D, Liu Z. Quantification of microstructural features and prediction of mechanical properties of a dual-phase Ti-6Al-4V alloy. Materials (Basel, Switzerland). 2016;9(8).

42. Higgins TF. Distal femoral fractures. J Knee Surgery. 2007;20(1):56-66.

43. Egol KA, Kubiak EN, Fulkerson E, Kummer FJ, Koval KJ. Biomechanics of locked plates and screws. J Orthop Trauma. 2004;18(8):488-93.

44. Schütz M, Südkamp NP. Revolution in plate osteosynthesis: new internal fixator systems. J Orthop Sci. 2003;8(2):252-8.

45. Ring D, Kloen P, Kadzielski J, Helfet D, Jupiter JB. Locking compression plates for osteoporotic nonunions of the diaphyseal humerus. Clin Orthop Relat Res. 2004;425:50-4.

46. Khan SN, Cammisa FP Jr, Sandhu HS, Diwan AD, Girardi FP, Lane JM. The biology of bone grafting. J Am Acad Orthop Surg. 2005;13(1):77-86.

47. Vidyadhara S, Vamsi K, Rao SK, Gnanadoss JJ, Pandian S. Use of intramedullary fibular strut graft: a novel adjunct to plating in the treatment of osteoporotic humeral shaft nonunion. Int Orthop. 2009;33(4):1009-14.

\section{Publisher's Note}

Springer Nature remains neutral with regard to jurisdictional claims in published maps and institutional affiliations. 